\title{
EFFECT OF STUDENTS THAT MUST REPEAT A COURSE IN THE DISTRIBUTION AND CAPACITY OF GROUPS
}

\author{
Lourdes Sánchez-Guerrero, Beatriz A. González-Beltrán, Josué Figueroa-González, \\ \& Silvia B. González-Brambila \\ Systems Department, Universidad Autónoma Metropolitana (Mexico)
}

\begin{abstract}
In educational institutions, there is a need in the right use of human resources. Consider, for example, the number of groups for certain courses, the offer of professors and spaces is limited, and many times, there is many students that desire a certain course and for reasons of capacity and availability, it is not possible to satisfy their demands. Sometimes, the fact that students must repeat a course, is considered to have only academic relevance, however, this issue can have implications in other topics, for example, the resources one. In order to have a better idea of how much does this affect in a superior institution, this work presents a statistical analysis of the effect of students that must take a course twice and how this affects the available spaces for those who will take it for first time. For this were analyzed the eight more demanded engineering courses in a Mexican university.
\end{abstract}

Keywords: Measurement in education, educational management, educational analytics, students' performance impact.

\section{Introduction}

In the Mexican Universidad Autonoma Metropolitana (UAM), when a student does not approve a course, has the chance of taking it one more time in a classroom, after that, it only could approve through an special exam called "Recuperation Exam". The problem when a student takes a course for a second time is that probably, it would be using a place than could have been used by a student that would take this course for first time, causing that this student has to wait another scholar period for taking it. It is clear that there is a problem with students that must take a certain course twice after not approving the course in their first try, causing that the total of spaces in a group were reduced for those students who will take the course for first time.

This is an interesting topic, the fact that students do not approve a course clearly has an impact in their studies progress, however many times it is not considered the impact that this could have in other areas of the educative environment.

For having a better idea of the impact of this problem, a statistical analysis for showing the proportion of students in a course that take the course for first or second time is proposed. Are considered four of the most demanded Engineering courses at UAM, which also have as prerequisite another course. For the analysis, were considered the number of students that approved a previous course and the total of students that did not approve the later one. Then is presented, using information visualization techniques as mentioned by Herman (2000), with these techniques are presented the information of students that are taking the course for first time, those ones for second time and the number of students that could not be registered for the course.

At UAM, there are three scholar periods per year named as the year followed by the letter I, P, O which represents Winter (I), Spring $(\mathrm{P})$ and Fall $(\mathrm{O})$ according the season when a new scholar period starts. There are new coming students in the periods of Spring and Fall (P and $\mathrm{O}$ ).

This work is part of a bigger analysis which main goal is generating a visual system, which shows many statistics about an educative environment. Something that nowadays is necessary due to the amount of data and the need of taking decisions based on information that in a textual way would be very difficult to analyze and it is related with the concept of Learning analytics proposed by Siemens (2011). 


\section{Most demanded courses at UAM}

At UAM, every engineering study program is composed by different groups of courses, but all of the 10 programs taught in the university, have a common group, this is called the General Branch which is composed by 18 courses as shown in UAM (2020). This group of courses encompass almost the first year of any engineering student. Because all the students take this courses, they are considered the most demanded, however because of the different dependences between these courses and the way in which students progress in their studies, the four most demanded among these courses are presented, among the scholar period, which corresponds to them, in Table 1.

Table 1. Most demanded courses and their characteristics.

\begin{tabular}{|l|c|l|}
\hline \multicolumn{1}{|c|}{ Course } & Scholar period & \multicolumn{1}{c|}{ Depends on } \\
\hline Compliments of Mathematics & 2 & Introduction to Mathematics \\
\hline Introduction to Calculus & 2 & Introduction to Mathematics \\
\hline Introduction to Programming & 3 & $\begin{array}{l}\text { Compliments of Mathematics } \\
\text { and Introduction to Calculus }\end{array}$ \\
\hline Differential Calculus & 3 & Introduction to Calculus \\
\hline
\end{tabular}

There are courses, which are for the first grade students, it is expected that these ones have a considerable demand; however, this courses do not represent a problem for the students that are going to take them for first time. UAM because the university assure that all of the new coming students have all their courses. However, as the students advance and begin to not approving courses, the number of places start to reduce.

\section{Analyzing courses}

For analyzing every course of Table 1, were considered from 2014 to 2018, which comprises 15 scholar periods, at UAM there are three scholar periods per year, and were obtained:

- Total of students that approve the previous course which represents the total of candidates for the next one.

- Total of students that did not approve the analyzed course, this number represents the total of students that must take another time the course.

- Total of students that took the course, considering those that take it for first time and those that take it for second time.

Considering this, for each course was generated a time graph, which shows the distribution over time of total of students that could take for first time the course, this means, and the ones that approved the prerequisite course in the former scholar period, the total of students that took the analyzed course for first and second time.

\subsection{Compliments of mathematics}

For taking the course Compliments of Mathematics, is necessary approving Introduction to Mathematics, those students that in the previous scholar period approved this one, are candidates for taking Compliments. Figure 1 presents:

- Total of students that took Compliments of Mathematics (Total).

- Total of students that were candidates for Compliments of Mathematics, this is, the ones that approved Introduction to Mathematics in the previous scholar period (Possible).

- Students that were allowed to take again Compliments of Mathematics, this is, students that in the previous scholar period did not approve it and still have a second chance (Could take again)

- From those students, those who took the course in (Second time).

- Students that took the course for first time (First time).

\subsection{Introduction to calculus}

In order to take Introduction to Calculus is necessary approving Introduction to Mathematics, those students that in the previous scholar period approved this one, are candidates for taking Introduction to Calculus. Figure 2 presents:

- Total of students that took Introduction to Calculus (Total).

- Total of students that were candidates for Introduction to Calculus, this is, the ones that approved Introduction to Mathematics in the previous scholar period (Possible). 
- Students that were allowed to take again Introduction to Calculus, this is, students that in the previous scholar period did not approve it and still have a second chance (Could take again).

- From those students, those who took the course in (Second time).

- Students that took the course for first time (First time).

Figure 1. Demand and students that took Compliments of Mathematics.

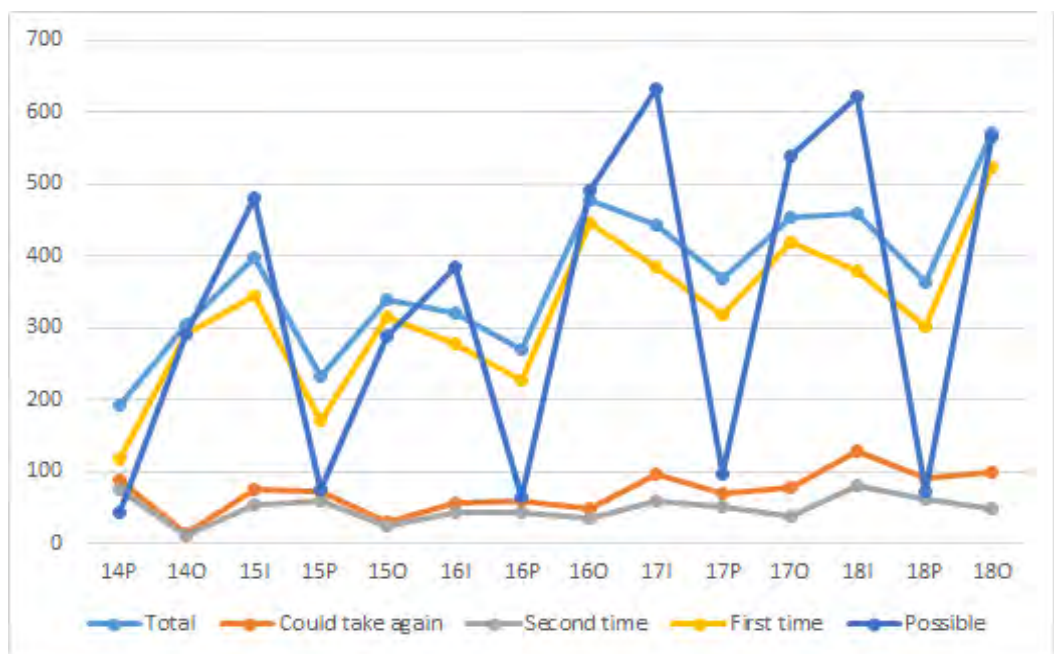

Figure 2. Demand and students that took Introduction to Calculus.

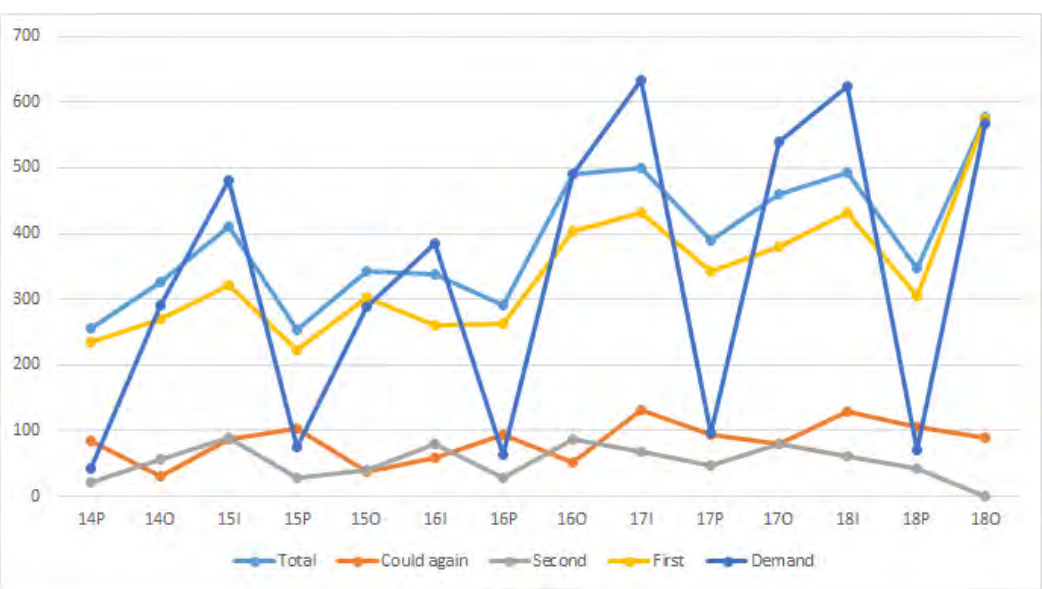

\subsection{Introduction to programming}

In order to take Introduction to Programming is necessary approving Compliments of Mathematics; those students that in the previous scholar period approved this one, are candidates for taking Introduction to Programming. Figure 3 presents:

- Total of students that took Introduction to Programming (Total).

- Total of students that were candidates for Introduction to Programming, this is, the ones that approved Compliments of Mathematics in the previous scholar period (Possible).

- Students that were allowed to take again Introduction to Programming, this is, students that in the previous scholar period did not approve it and still have a second chance (Could take again)

- From those students, those who took the course in (Second time).

- Students that took the course for first time (First time).

\subsection{Differential calculus}

In order to take Differential Calculus, is necessary approving Introduction to Calculus, those students that in the previous scholar period approved this one, are candidates for taking Differential Calculus. Figure 4 presents: 
- Total of students that took Differential Calculus (Total).

- Total of students that were candidates for Differential Calculus, this is, the ones that approved Introduction to Calculus in the previous scholar period (Possible).

- Students that were allowed to take again Differential Calculus, this is, students that in the previous scholar period did not approve it and still have a second chance (Could take again).

- From those students, those who took the course in (Second time).

- Students that took the course for first time (First time).

Figure 3. Demand and students that took Introduction to Programming.

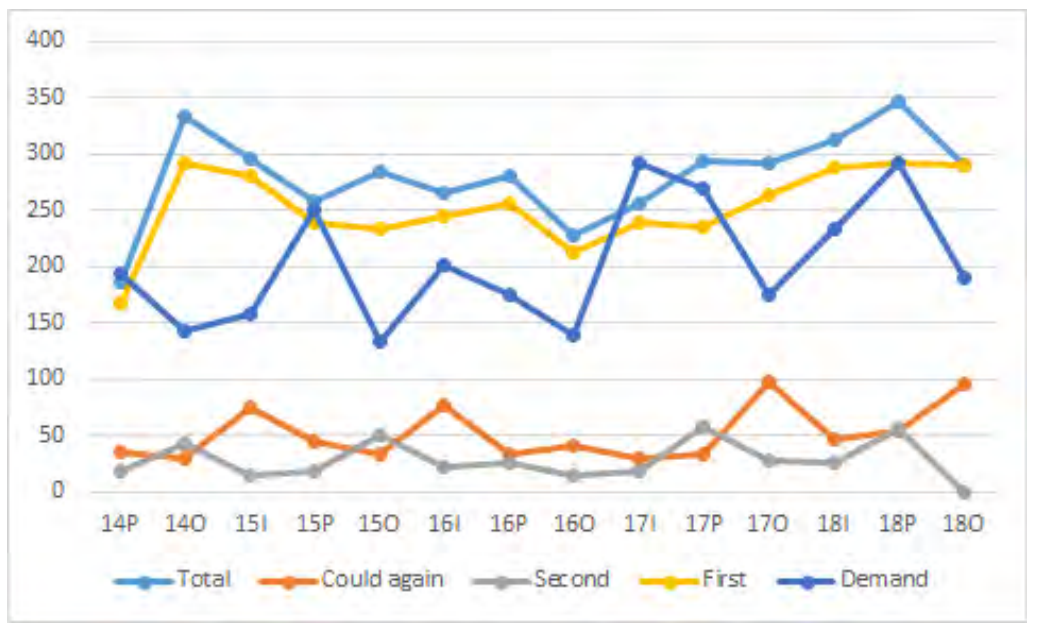

Figure 4. Demand and students that took Differential Calculus.

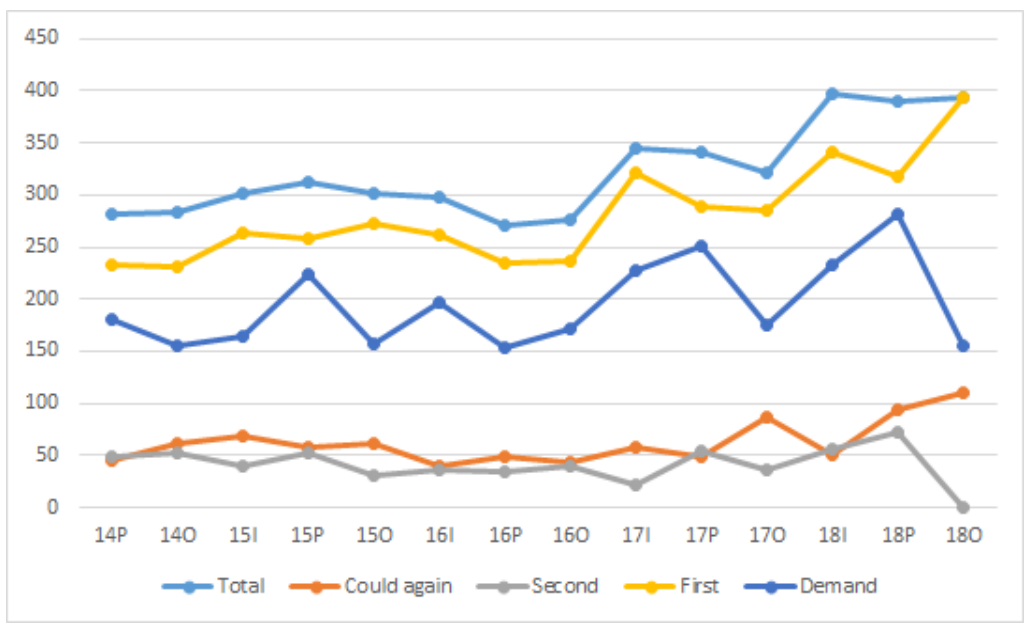

\section{Analysis}

Considering the graphs presented in Figures 1 to 4, it is clear that the courses which have more problems are Compliments of Mathematics and Introduction to Calculus (Figure 1 and Figure 2). In these courses, the demand considering the students that approved the previous course is bigger than the total of students that took course. There are scholar periods in which the demand is very low, this is because the previous course, Introduction to Mathematics is offered to new coming students, and after a scholar period where there were not new students, the demand of places for the next course comes down drastically.

The other two courses do not have a several issue, the demand of places due to students that approved the previous course it is not considerable, and more students took these courses. This is because some of the previous courses (Compliments of Mathematics and Introduction to Calculus) are a bit more complicate and more students did not approve them, so the demand comes down. Also, more students did not approve the former courses in their second try and this makes it impossible to them to take the course again. 
Analyzing the behavior of students that did not approve a course, the total of them that could take the course again is not considerable, but in general could be told that not all the students that did not approve and could take the course again take it in the next scholar period. This causes an extra delay in their studies.

\section{Conclusions}

Universities generate a lot of information related with many topics, presenting this information in a clear way allows its analysis for discovering if there are problems or situations that need the attention of authorities. Having the data just as raw versions with thousands of registers that are not analyzed is something that in the era ok information and knowledge could not be allowed in any superior institution.

Goal of this work was determining if there is a problem related with offer and demand in four courses, which are considered as the most demanded in all the engineering programs. Results show that two of them have problems every certain scholar period where the demand is greater than the students that took the courses. This means that a certain number of students could not take them provoking a delay in their studies. This also occurs to those students that have failed once in the course, here, the delay is twice, one because of not approving and another due to they could not take the course again, this means that a course that should be approved in one scholar period, could be approved in at least 3 (a year considering the scholar calendar of UAM).

This information exists, but as raw data it is almost impossible to discover this kind of patterns or behavior, it is only when the data is presented in a visual way that the problem raises and measures could be taken to solve it. As an initial stage of a bigger project related with showing a lot of information at UAM, results from this work allows discovering the problems that exists in two courses. This study can be applied to all the courses at UAM, this could help improving the number of courses that are programmed every scholar period and also taking measurements for helping students during their studies so their advance could be as expected and desired for both, the institution and students themselves.

\section{References}

Herman, I., Melançon, G., \& Marshall, M. S. (2000). Graph visualization and navigation in information visualization: A survey. IEEE Transactions on visualization and computer graphics, 6(1), 24-43.

Siemens, G., \& Long, P. (2011). Penetrating the fog: Analytics in learning and education. EDUCAUSE review, 46(5), 30 .

UAM Azcapotzalco, DCBI, followed by last names and initials of other authors if any. (January 2020). Retrieved May 20, 2020, from: http://cbi.azc.uam.mx/?page_id=70 